\title{
Effect of the Frequency of Probiotic Use on the Productivity and Incubation Properties of Eggs of the Meat Production Direction
}

\section{A A Ovchinnikov, E V Matrosova, L Yu Ovchinnikova, E M Yermolova, and D A Konovalov}

South Ural State Agrarian University, Troitsk, Chelyabinsk Region, Russia

\section{Abstract}

The use of probiotics Levisel SB Plus and Cellobacterin-T in the amount of 0.50 $\mathrm{kg} / \mathrm{t}$ of mixed fodder in the diet of young herd replacement of the meat direction during the growing period from 3 to 45 days allowed to get homogeneity by 20.9 and $13.1 \%$ above the analogues of the control group. Probiotic feed additive Levisel SB Plus increased the number of fertilized eggs by $1.96 \%$, hatchability -- by 0.90 $\%$, hatchery waste decreased by $2.7 \%$, feed costs decreased by $9.6 \%$. However, the best production results were shown by the group with a similar rate of probiotic

Corresponding Author:

A A Ovchinnikov

Received: 25 October 2019

Accepted: 15 November 2019

Published: 25 November 2019

Publishing services provided by Knowledge E

(c) A A Ovchinnikov et al. This article is distributed under the terms of the Creative Commons Attribution License, which permits unrestricted use and redistribution provided that the original author and source are credited.

Selection and Peer-review under the responsibility of the AgroSMART 2019 Conference Committee.

\section{G OPEN ACCESS}

Cellobacterin-T introduction, which had these indicators, respectively, of $2.0 \%, 1.28$, 4.2 and $10.4 \%$.

Keywords: a hen laying hens, productivity, incubation, feed costs, feed payment with products.

\section{Introduction}

The use of fourth-generation probiotic feed additives in the diets of farm animals and poultry in terms of their productive effect in many respects exceeds monocomponent bacterial cultures [3]. They have a multifunctional effect on the processes of digestion, normalization of the bacterial background, increasing the immune status of the host, which ultimately affects the safety of the livestock, productivity, economic efficiency and profitability of production.

Industrial poultry production is associated with a certain degree of risk of disease, both contagious and non-contagious. To prevent bacterial infections and raise the immune status of the organism in the poultry diet include probiotic feed additives throughout the production cycle with the recommended rate of introduction recommended by the producer. They not only normalize the normal flora of the intestine, increase the titre of antibodies to the antigens of bacterial infections, that is, they allow prolonging the duration of active immunity [1, 2, 7]. However, the daily use of probiotics in many ways leads to higher prices, especially for imported products, which reduces the profitability of the industry. 
The question arises whether probiotics can be used phasewise during the poultry production cycle, i.e. during the most demanding periods of runaway and peak production, at a time of declining productivity, when the body is weakened and support is needed to improve the survival of the stock.

These "critical" periods in the production cycle at each enterprise are established on the basis of a set of indicators of the veterinary state of the livestock, production and economic.

Therefore, the aim of the studies was to establish the effectiveness of the use of various probiotics in the diet of laying hens of meat production in different periods of the productive cycle. The objectives of the research were to compare the poultry's egg productivity, egg weight, incubation rates, livestock safety and to calculate economic efficiency per unit of production.

\section{Methods of the Research}

In the conditions of the poultry farm "Ravis-Ptitsefabrika Sosnovskaya" LLC of the Chelyabinsk region, on the breeding reproducer II-th order "Sandy department", in 2015, was conducted scientific and economic experience in three groups of courses cross "ISA Hubbard F--15", 100 heads in each, being in the same conditions of maintenance and feeding. Formation of the experimental groups was carried out by the repair youngster, who also received probiotics Levisel SB Plus (II experimental group) and Cellobacterin-T (III experimental group) at the age of 3--45 days in a dosage of $0,50 \mathrm{~kg} / \mathrm{t}$ of mixed fodder during the growing period. Poultry hens II and III of the experimental group probiotics were fed in the same dosage during the period of $5 \%$ of oviposition at the age of 142--187 days, the peak of productivity -- 241--270 days and its decrease -- by 316--337 days.

Egg productivity of hens was accounted for daily on the basis of gross collection of eggs per group, and the safety of the herd was accounted for by the death of the hens and the cause of the pathological anatomical autopsy was established. The incubation properties of the egg were determined by its fertility, hatchability and hatchability, as well as by the waste of incubation due to defects in the egg.

Based on the actually fed feed and eggs received, as well as the egg mass, feed costs and feed payments were calculated. The resulting material was processed biometrically to determine the level of confidence. 


\section{Results of the Research}

The egg production of chickens depends on many factors, one of which is the homogeneity of the group of repaired young animals. Whereas in control group I this indicator was $66.3 \%$ when growing young stock and transferring it to the parent stock, in group 2 it was $20.9 \%$ higher, in group 3 it was $13.1 \%$ higher, and the yield of business young people was 95.7 and $96.5 \%$, respectively, compared to $94.6 \%$ in the control group.

As a result, during the period of distribution (168--175 days) birds of the second experimental group had productivity 2.0 times higher than in the control group, and in the third experimental group -- 1.4 times higher than in the control group (tab. 1). This pattern is traced in subsequent age periods with a significant difference at the end of oviposition.

TABLE 1: Egg productivity of chickens during the period of scientific and economic experience per mediumsized laying hens, pcs. $(\mathrm{X} \pm$ " $\mathrm{x}, \mathrm{n}=100)$.

\begin{tabular}{|c|c|c|c|c|}
\hline \multicolumn{2}{|c|}{ Age } & \multicolumn{3}{|c|}{ Group } \\
\hline & & 1 control & 2 experimental & 3 experimental \\
\hline 148--175 & day & $1,28 \pm 0,01$ & $2,52 \pm 0,03$ & $1,81 \pm 0,02$ \\
\hline 176--203 & & $18,71 \pm 0,03$ & $21,80 \pm 0,02^{* * *}$ & $21,67 \pm 0,03^{*}$ \\
\hline 204--231 & & $23,09 \pm 0,001$ & $23,71 \pm 0,002^{* * *}$ & $24,83 \pm 0,06^{* * *}$ \\
\hline 232--259 & & $22,25 \pm 0,003$ & $23,41 \pm 0,002^{* * *}$ & $24,03 \pm 0,003^{* * *}$ \\
\hline 260--287 & & $20,85 \pm 0,004$ & $22,40 \pm 0,005^{* * *}$ & $22,75 \pm 0,08^{* * *}$ \\
\hline 288--315 & & $19,02 \pm 0,004$ & $20,93 \pm 0,004^{* * *}$ & $20,96 \pm 0,005^{* * *}$ \\
\hline 316--343 & & $16,39 \pm 0,006$ & $19,15 \pm 0,005^{* * *}$ & $19,25 \pm 0,09^{* * *}$ \\
\hline 344--371 & & $13,93 \pm 0,004$ & $16,81 \pm 0,006^{* * *}$ & $17,62 \pm 0,004^{* * *}$ \\
\hline \multicolumn{2}{|c|}{ average } & $16,94 \pm 2,48$ & $18,84 \pm 2,47$ & $19,12 \pm 2,61$ \\
\hline
\end{tabular}

Here and further: * -- $\mathrm{P} \leq 0,05 ;{ }^{* *}-\mathrm{P} \leq 0,01 ;{ }^{* * *}-\mathrm{P} \leq 0,001$.

As a result, the average egg-laying rate of the hens of the first control group for the productive period was at the level of 16.94 eggs, in the second control group it was 11.2 $\%$ higher, in the third control group it was $12.9 \%$ higher, amounting to 18.84 eggs and 19.12 eggs, respectively.

It is typical to note that the egg weight of the control and experimental groups during the whole egg-laying period did not have any reliable differences and was within the limits: at the age of 168 days 48.20--48.67 g, in the peak of productivity (204--231 days) -- 58.54--58.82, in the final period (344--371 days) -- 66,50--66,99 г. 
Being on the same diet probiotics influenced the biochemical parameters of the hatching egg. In terms of vitamin A egg content in the yolk of the hens in the experimental group at the age of 204--231 days it was higher than the control group I by 8.2 $\%$, in the experimental group III -- by $21.9 \%(P \leq 0.05)$. The thickness of the shells in all groups of eggs was equal $(0.35--0.37 \mathrm{~mm})$, as well as the acid number (5.18--5.35) and density $\left(1.08 \mathrm{~g} / \mathrm{cm}^{3}\right)$.

Periodic use of probiotics in the diet of laying hens increased the safety of the herd in Group II in comparison with Group I by $1.3 \%$, in Group III -- by $2.1 \%$, which eventually affected the yield of egg masses in the calculation of the average laying hen, which in Group II was higher than the control hen by $11.9 \%$, in Group III -- by $13.3 \%$ (Table 2).

TABLE 2: Herd safety and egg mass output to the middle layer ( $X \pm \pm$ "x).

Index
Livestock of laying hens, head.
Population safety, \%
Produced on the laying hens of eggs, pcs.
Average weight of an egg, $\mathrm{g}$
Egg mass output on the laying hens, kg

\begin{tabular}{|c|c|c|}
\hline \multicolumn{3}{|c|}{ Group } \\
\hline 1 control & 2 experimental & 3 experimental \\
\hline 100 & 100 & 100 \\
\hline 93.5 & 94.8 & 95.6 \\
\hline $16,94 \pm 2,48$ & $18,84 \pm 2,47$ & $19,12 \pm 2,61$ \\
\hline $60,41 \pm 2,20$ & $60,78 \pm 2,24$ & $60,64 \pm 2,21$ \\
\hline $1,023 \pm 0,141$ & $1,145 \pm 0,145$ & $1,159 \pm 0,151$ \\
\hline
\end{tabular}

The quality of the hatching egg influences the hatching results. Indicators of the results of incubation of a series of control lays during the period of maximum laying of hens are shown in Table 3.

TABLE 3: Hatching qualities of laying hens eggs $(X \pm " x, n=8)$.

Index
Eggs laid for incubation, pcs.
Fertilized eggs, pcs. \%
Chickens out, head.
Egg hatchability, \%.
Breeding of young animals, \%
Incubation waste, pcs.
\%

\begin{tabular}{|c|c|c|}
\hline \multicolumn{3}{|c|}{ Group } \\
\hline 1 control & 2 experimental & 3 experimental \\
\hline 300 & 300 & 300 \\
\hline $272,50 \pm 1,59$ & $278,38 \pm 1,64^{*}$ & $281,50 \pm 0,53^{* * *}$ \\
$90,83 \pm 0,53$ & $92,79 \pm 0,55^{*}$ & $93,83 \pm 0,18^{* * *}$ \\
\hline $251,50 \pm 2,63$ & $259,37 \pm 1,81^{* *}$ & $263,38 \pm 1,56^{* * *}$ \\
\hline $92,28 \pm 0,54$ & $93,18 \pm 0,54$ & $93,56 \pm 0,61$ \\
\hline $83,8 \pm 0,88$ & $86,5 \pm 0,65$ & $88,0 \pm 0,52^{*}$ \\
\hline $48,50 \pm 2,63$ & $40,63 \pm 1,81^{* *}$ & $36,62 \pm 1,56^{* *}$ \\
\hline 16.2 & 13.5 & 12.0 \\
\hline
\end{tabular}

The use of probiotics in the diet of experimental chickens increased the number of fertilized eggs by $1.96 \%$ in Group II $(P \leq 0.05)$ and by $2.0 \%$ in Group III $(P \leq 0.001)$ 
compared to the control group. At the same time, the hatchability of eggs in experimental groups of birds also exceeded the control group by $0.90 \%$ in II and $1.28 \%$ in III experimental group, amounting to 93.18 and $93.56 \%$, respectively. Reduce the number of young hatching wastes, the value of which may be influenced not only by external factors, but also by the qualitative indicators of the produced eggs from the breeding stock. In the group of laying hens receiving the probiotic Levisel SB Plus (group II) in comparison with the control waste of incubation decreased by $2.7 \%$, with the addition of Cellobacterina-T (group III) -- by $4.2 \%$, making up 13.5 and $12.0 \%$, respectively.

However, the difference does not make it possible to compare the causes of the egg defect, which is important for poultry breeding. Our analysis of the reasons for the egg withdrawal during the incubation period is presented in Table 4.

The decrease in the number of unfertilized eggs in experimental groups in comparison with the control group is most likely associated with the qualitative composition of the egg, the content of biologically active substances in it, in particular, vitamin A, which directly affects the efficiency of fertilization. With the addition of probiotic Levisel SB Plus, the incubation waste on this basis decreased by $3.5 \%(P \leq 0.05)$, with Cellobacterin$\mathrm{T}$-- by $6.2 \%$ ( $\mathrm{P} \leq 0.001)$. At the same time, the number of false neoplates in all groups was the same in the range of $11.3-12.0 \%$, which is likely to be related to roosters, their number in the barn or their age.

A defect such as the "blood-ring" associated with the death of the embryo at the stage of formation of the yolk blood circulation between the groups also did not have a reliable difference and is likely to be associated with vitamin nutrition of laying hens. Decrease in hatchability due to egg culling with a sign of "tumak" in the experimental groups, although it was insignificant (0.9--1.0 \%) is likely to be related to the human factor, which is currently the primary factor in the production of any type of agricultural products. The percentage of hatching eggs abandoned due to frozen embryos in all groups was high and varied from $16.8 \%$ in control group I to $17.6 \%$ in control group II and to $17.1 \%$ in control group III, but in absolute terms it decreased by 1.0 eggs in group II and 1.88 eggs in group III $(\mathrm{P} \leq 0.05)$. While the departure due to the " suffocates" in absolute terms was close in value and in relative terms tended to increase. This indicator could be influenced by the infectious bacterial background of the poultry house and the planning of veterinary treatments.

The obtained difference in productivity of laying hens and quality of hatching eggs when using the studied probiotic feed additives in the diet allowed to calculate feed costs per unit of production (Table 5). 
TABLE 4: Reasons for the departure of the hatching egg $(X \pm " x, n=8)$.

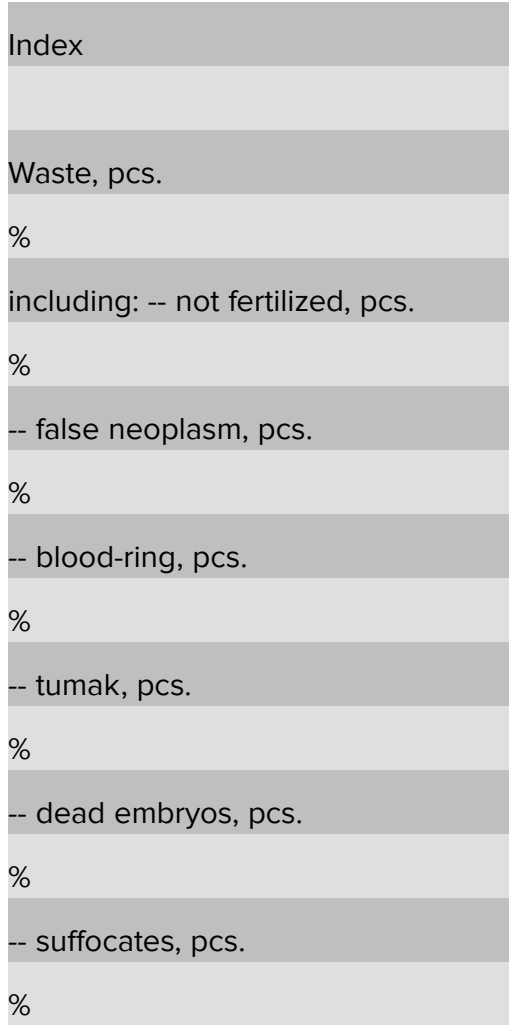

\begin{tabular}{|c|c|c|}
\hline \multicolumn{3}{|c|}{ Group } \\
\hline 1 control & 2 experimental & 3 experimental \\
\hline $48,50 \pm 2,63$ & $40,63 \pm 1,81^{* *}$ & $36,62 \pm 1,56^{* *}$ \\
\hline 16.2 & 13.5 & 12.0 \\
\hline $27,50 \pm 1,59$ & $21,63 \pm 1,64^{*}$ & $18,50 \pm 0,53^{* * *}$ \\
\hline 56.7 & 53.2 & 50.5 \\
\hline $5,50 \pm 1,12$ & $5,12 \pm 0,77$ & $4,38 \pm 0,86$ \\
\hline 11.3 & 12.7 & 12.0 \\
\hline $3,25 \pm 0,45$ & $2,50 \pm 0,38$ & $2,88 \pm 0,67$ \\
\hline 6.7 & 6.1 & 7.9 \\
\hline-- & 0.37 & $0,38 \pm 0,50$ \\
\hline-- & 0.9 & 1.0 \\
\hline $8,13 \pm 0,67$ & $7,13 \pm 0,40$ & $6,25 \pm 0,25^{*}$ \\
\hline 16.8 & 17.6 & 17.1 \\
\hline $4,13 \pm 0,95$ & $3,88 \pm 0,69$ & $4,25 \pm 0,62$ \\
\hline 8.5 & 9.5 & 11.5 \\
\hline
\end{tabular}

TABLE 5: Feed costs for hatching eggs for the average laying hen.

Index
Feeded over the productive period:
-- Feed, kg
-- of metabolic energy, MJ.
-- raw protein, kg
Eggs produced, pcs.
Spent on getting 10 eggs:
-- Feed, kg
-- of metabolic energy, MJ.
-- raw protein, $\mathrm{g}$
-- in \% to the control group

\begin{tabular}{|c|}
\hline 1 control \\
\hline 31.95 \\
\hline 86.18 \\
\hline 5.22 \\
\hline 135.51 \\
\hline 2.36 \\
\hline 6.36 \\
\hline 385 \\
\hline
\end{tabular}

\begin{tabular}{|c|c|}
\hline Group & \\
\hline 2 experimental & 3 experimental \\
\hline 32.14 & 32.325 \\
\hline 86.69 & 87.20 \\
\hline 5.25 & 5.28 \\
\hline 150.73 & 152.92 \\
\hline & \\
\hline 2.13 & 2.11 \\
\hline 5.75 & 5.70 \\
\hline 348 & 345 \\
\hline 90.4 & 89.6 \\
\hline
\end{tabular}

Thus, if in control group I $2.36 \mathrm{~kg}$ of complete feed, $6.36 \mathrm{MJ}$ of metabolic energy and $385 \mathrm{~g}$ of raw protein were used per ten eggs, the use of probiotic Levisel SB Plus reduced feed costs by $9.6 \%$, and Cellobacterin-T -- by $10.4 \%$.

However, one feed cost cannot fully characterize the economic efficiency of probiotic feeding technique by the periods of the productive cycle and as a supplement it is 
required to calculate the cost of feed payment by products, both in value and in physical terms (tabl. 6).

TABLE 6: Economic efficiency of production of hatching eggs of meat production direction (average for the group).

\begin{tabular}{|c|c|c|c|}
\hline \multirow[t]{2}{*}{ Index } & \multicolumn{3}{|c|}{ Group } \\
\hline & 1 control & 1 experimental & 2 experimental \\
\hline $\begin{array}{l}\text { Feeded over the productive period } \\
\text { of mixed fodder, } \mathrm{kg}\end{array}$ & 2987.32 & 3046.68 & 3090.27 \\
\hline $\begin{array}{l}\text { Feeded with feed additives, kg: } \\
\text { Levisel SB Plus Cellobacterin-T }\end{array}$ & --- & $0.43--$ & --0.45 \\
\hline Cost of fodder, rub. & 40583 & 41388 & 41987 \\
\hline $\begin{array}{l}\text { Cost of feed additives, rub: Levisel } \\
\text { SB Plus Cellobacterin-T }\end{array}$ & --- & $216--$ & -- 133 \\
\hline $\begin{array}{l}\text { Total cost of feed and feed } \\
\text { additives, rub. }\end{array}$ & 40583 & 41604 & 42120 \\
\hline Eggs produced, pcs. & 12670 & 14289 & 14619 \\
\hline $\begin{array}{l}\text { Eggs made, pcs.: -- per every } 100 \mathrm{~kg} \\
\text { of mixed fodder fed }\end{array}$ & 157.24 & 173.88 & 175.38 \\
\hline in $\%$ to the control group & 100.0 & 110.6 & 111.5 \\
\hline -- per each fed 1000 rubles of food & 312.20 & 343.25 & 347.08 \\
\hline in $\%$ to the control group & 100.0 & 110.0 & 111.2 \\
\hline
\end{tabular}

During the reproductive cycle, 0.43 and $0.45 \mathrm{~kg}$ of probiotics were fed to the hens of the experimental groups, which resulted in a rise in the cost of the total number of fed cows by 216 rubles in II and 133 rubles. -- in the third experimental group. The calculated productivity of chickens, taking into account the safety of the livestock, allowed the control group to produce 157.24 eggs for every $100 \mathrm{~kg}$ of fully fed mixed fodder, and 312.20 eggs for every 1000 rub. fed fodder, while in the second experimental group the payment for fodder increased by 10.0--10.6 \%, in the third experimental group -- by $11.2--11.5 \%$.

\section{Discussion}

Many probiotics scientists believe that probiotics belong to the group of vitagens -organic bacterial additives that have a biogenic effect in the body [8] in maintaining the constancy of the intestinal normoflora, increasing the hydrolytic processes of protein, lipid and carbohydrate metabolism. They are used throughout the entire production cycle [4-6], which does not affect the technological process of poultry meat production. 
Our studies show that with constant control of the immune status of the poultry organism, controlled by antibody titre to the most widespread diseases, the use of probiotics can be reduced and included in the composition of complete feed during critical periods of the productive cycle as an aid to the body in overcoming the pressing of foreign microflora, as well as the prolongation of postvaccinal immunity. Most often it is the period of rearing the young stock at the age of 3--45 days, when transferring the poultry to the parent flock and the beginning of egg-laying (168--175 days), in the peak of egg-laying (204--231 days) and at its completion (344--371 days). In this case it is possible to increase the homogeneity of the breeding stock of hens by 13.1--20.9\%, increase the egg productivity by $11.2-12.9 \%$, improve the quality of hatching eggs and reduce the cost of feed per unit of product. At the same time, of the two probiotics compared, Cellobacterin-T showed a higher effect of use: the safety of the herd compared to the group receiving Levisel SB Plus was higher by $0.8 \%$, the conclusion of the herd -- by $1.5 \%$, hatchability -- by $0.38 \%$, feed costs decreased by $0.8 \%$.

\section{Conclusion}

It is expedient to use probiotic Cellobacterin-T in the diet of chickens of parental flock with the norm of input of $0,50 \mathrm{~kg} / \mathrm{t}$ of mixed fodder for the periods of productive cycle at the age of poultry 168--175, 204--231 and 344--371 days that will allow to increase profitability of production and to reduce costs per unit of production.

\section{References}

[1] Grozina, A.A. (2012). Composition of gastrointestinal microflora in broiler chickens under the influence of probiotics and antibiotics (according to t-rflp-rt-pcr data). Agricultural biology, no. 6, pp. 46--58.

[2] Danilevskaya, N.V. (2012). Influence of probiotics on post-stvaccinal immunity of birds. Russian Veterinary Journal, no. 2, pp. 28--30.

[3] Manukyan, V., Javadov, E., Dmitrieva, M., Laptev, G., Nikonov, I., Novikova, N., llyina, L. (2013). Application of enzymatic probiotic in feeding broiler chickens. Poultry and poultry products, no. 5, pp. 22--24.

[4] Ovchinnikov, A.A., Plastinina, Yu.V., Ishimov, V.A. (2008). Comparative application of probiotics in poultry farming. Zootechniya, no. 5, pp. 8--10.

[5] Ovchinnikov, A.A., Plastinina, Yu.V., Ishimov, V.A. (2007). Efficiency of the probiotics application in the broiler chicken diets. Proceedings of the scientific-practical 
conference of the pharmacologists of the Russian Federation: Pharmacological and ecotoxicological aspects of the veterinary medicine. Troitsk, pp. 216--218.

[6] Ovchinnikova, L.Yu., Matrosova, Yu.V., Ishimov, V.A. (2011). Meat productivity of the broiler chickens when used in the probiotic diet. Agrarian Bulletin of the Urals, no. 5, p. 46.

[7] Tarakanov, B. (2000). Mechanism of action of probiotics on the microflora of the digestive tract and animal organism. Veterinary Medicine, no. 1, pp. 47--54.

[8] Fisinin, V.I., Suray, P. (2013). Intestinal immunity in birds: facts and thoughts (review). Agricultural biology, no. 4, pp. 3--23. 